\title{
TEMPORAL ANALYSIS OF THE ACCELERATION AND DECELERATION PHASES FOR VISUAL SACCADES
}

\author{
Hsuan-Hung Lin', Yung-Fu Chen ${ }^{4}$, Tainsong Chen ${ }^{2}$, Tzu-Tung Tsal ${ }^{3}$, Kuo-Hsien Huang ${ }^{1}$ \\ ${ }^{1}$ Department of Management Information Systems, Chungtai institute of Health Sciences and \\ Technology, Taichung, Taiwan \\ ${ }^{2}$ Institute of Biomedical Engineering, National Cheng-Kung University, Tainan, Taiwan \\ ${ }^{3}$ Department of Neurology, National Cheng-Kung University, Tainan, Taiwan \\ ${ }^{4}$ Department of Computer Science and Information Engineering,
}

Da-Yeh University, Chang-Hua, Taiwan

\begin{abstract}
Previous studies showed that the relation for product of peak velocity and duration against saccadic amplitude was highly linear correlated. The velocity profile was related as a triangular profile and referred to the saccadic amplitude as an integration of the profile, so that the amplitude is proportional to the product of peak velocity and duration. The saccadic amplitude can be described as a function of peak velocity and duration.

In this study, in addition to the triangular profile, the rational power function was applied to explain the above linear relation. The acceleration and deceleration phases can be described, respectively: with the different shape parameters $\left(n_{1}\right.$ and $\left.n_{2}\right)$.

Finally, we described the product of peak velocity and acceleration time relating to the acceleration amplitude, and the product of peak velocity and deceleration time relating to the deceleration amplitude. The results show that the acceleration and deceleration phase parameters could be used to accurately delineate the saccadic characteristics.
\end{abstract}

Biomed Eng Appl Basis Comm, 2004(December); 16: 355-362.

Keywords: Saccade, Velocity profile, Acceleration phase, Deceleration phase.

\section{INTRODUCTION}

Main sequence relations have been used to describe the dynamics of the saccadic eye movernents for years [I]. The duration is almost proportional to the amplitude, whereas the peak velocity and the

Received: June 9, 2004; Accepted: Oct 20, 2004

Correspondence: Tainsong Chen, Professor

Institute of Biomedical Engineering,

National Cheng-Kung University,

Tainan, Taiwan

E-mail: chents@mail.ncku.edu.tw amplitude relation could be described as an exponential function [2-3]. The peak velocity was proportional to the average velocity [4-5] and can be described as

$$
A=\frac{l}{c} \cdot D
$$

where $V_{m}$ is the peak velocity and $c$ is a constant, respectively

The relationship for the product of peak velocity and duration against saccadic amplitude, as indicated in Equation (1), was highly correlated with the correlation coefficient, $r=0.97$. According to the study of Van Opstal et al. [6], they related the velocity profile as triangular and referred the saccadic amplitude as an 
integration of the profile that the amplitude is proportional to $V_{m} D$. From our observation and derivation, in addition to the triangular profile, the rational power function could also be applied to explain the linear relationship between the saccadic amplitude and the product of peak velocity and duration [7]. The velocity profile is asymmetric for large amplitudes and its acceleration and deceleration phases can be described respectively as the following equation

$$
V(t)=\left\{\begin{array}{l}
I_{m}-\frac{I_{m 1}}{D_{n}^{n_{1}}}\left(D_{a}-t\right)^{n_{1}}, 0 \leq t \leq D_{a} \\
I_{m}-\frac{I_{m}^{n}}{D_{d}^{n}}\left(t-D_{n}\right)^{n}, D_{a}<t \leq D_{n}+D_{d}
\end{array}\right.
$$

where $D_{a}$ and $D_{d}$ represent the acceleration and deceleration duration; $n_{1}$ and $n_{2}$ also depict their shapes. The integration of $v(t)$ over time $(t)$ from 0 to $D_{a}+D_{d}$ approximates the saccadic amplitude, which can be described as a function of peak velocity and saccadic duration, that is:

$$
A=\frac{n_{1}}{n_{1}+1} V_{m} D_{a}+\frac{n_{2}}{n_{2}+1} V_{m} D_{d}
$$

in which the first term is the acceleration amplitude $\left(A_{a}\right)$ and the second indicates the deceleration amplitude $\left(A_{d}\right)$. The velocity profile becomes symmetrical as the amplitude decreases. Then Eq. (3) can be modified to:

$$
A=\frac{n}{n+1} V_{m} D
$$

where $c$ in Equation (1) is replaced by $(n+1) / n$.

The goal of this study is to investigate more exhaustively the velocity profile of the visual-guided saccades for amplitudes extending to a larger range $\left(10^{\circ}-60^{\circ}\right)$. In addition to peak velocity, duration, acceleration fraction, and skewness, other parameters such as acceleration time, deceleration time, acceleration amplitude, and deceleration amplitude were also evaluated. The product of peak velocity and acceleration time $\left(V_{m} D_{a}\right)$ relating to the acceleration amplitude and the product of peak velocity and deceleration time $\left(V_{m} D_{d}\right)$ relating to the deceleration amplitude were investigated as well. The shape parameters of the acceleration and deceleration phases delineating the profile curvature, as shown in Equation (3), were also evaluated, which are shown to be valuable in delineating the saccadic dynamic characteristics.

\section{METHODS AND MATERIALS}

\subsection{Subjects and Experimental Paradigms}

Fifteen normal subjects (range 21 to 26 years with mean of 23.6) without history of neurological disease were recruited from graduate students of National Cheng Kung University and tested in the experiment. All subjects were given a neurological examination by a neurologist, one of the authors, Dr. Tsai, before the experiment; only those without clinical evidence of diseases were tested and recorded with Electrooculograph (EOG) technique. Subjects also took a visual test and were required to have at least $20 / 20$ visual acuity with or without optical correction before recording. The subjects were all informed of the purpose and procedures of the test.

Since the design of the light bar for our system spans from only $-30^{\circ}$ to $+30^{\circ}$ with $5^{\circ}$ intervals, the test was divided into two sessions: one for the amplitudes ranging from $10^{\circ}$ to $30^{\circ}$, the other extending the range to $35^{\circ}-60^{\circ}$. Based on the observation that the duration of acceleration phase is not significantly affected by initial position of eccentricity [8], the eccentric fixation paradigm was used for extending the amplitude to more than $30^{\circ}$. In order to eliminate subject's prediction, saccadic targets were displayed with pseudorandom amplitudes $\left(5^{\circ}-30^{\circ}\right.$ and $\left.35^{\circ}-60^{\circ}\right)$ and duration (1.2-2s). Each session lasted for 60 seconds. Subjects then took a 3-minute break after each test to prevent the influence of fatigue. The test was repeated at least 6 times for each subject. All the tests were performed in a dark cabin (Microtechnology 2000, Illinois). The subjects were asked to sit in a chair with a headrest to minimize head movement. An infrared camera was used to monitor the general condition of the subjects. Tests would be terminated if the subjects show nervousness or fatigue.

\subsection{Data Analysis}

Saccade onset was defined as the point $4 \mathrm{~ms}$ before the detected position with velocity threshold of $30^{\circ} / \mathrm{sec}$, whereas the offset was defined, in a similar way, as the position $4 \mathrm{~ms}$ after the last point where the velocity is still greater than the threshold. It was found that saccadic undershoot lay between $1 \%$ and $5 \%$ of the target amplitude [3]. Also, by considering that evaluated parameters were averaged and analyzed for various amplitudes, only saccades with accuracy greater than $95 \%$ were used for further analysis. Saccadic accuracy was determined according to the eye position error of the primary saccade. In order to compare with previous investigations, duration and peak velocity were evaluated and then the main sequence relations describing the relationship between 
duration and amplitude, and between the peak velocity and amplitude, were obtained.

The acceleration time was defined as the duration between the saccade onset and when the eye reached the maximum velocity, which was then subtracted from the duration for calculating the deceleration time. The acceleration amplitude was measured by mapping the time of the maximum velocity back to the position profile, and the deceleration amplitude was obtained by subtracting the acceleration amplitude from the saccadic amplitude accordingly.

Linear relations for the product of peak velocity and acceleration time were plotted against measured acceleration amplitude, and the product of peak velocity and deceleration time were plotted against deceleration amplitude. The slopes were then evaluated for estimating the values of $n_{1}$ and $n_{2}$ shown in Equation (3).

\section{RESULTS}

Mean values and standard deviations of the evaluated parameters are shown in Table 1 and 2, respectively, for the adductive and abductive saccades. Some of the parameters had also been used for the investigation of peak velocity and skewness relationship [9]. Although peak velocity of the abductive saccades for each amplitude is a little larger than the adductive, this factor doesn't reach significant difference. Figure 1 displays the main sequence relations and the relation for the product of peak velocity and duration against amplitude. As indicated in this figure, peak velocity and duration are very deviated for data that had been pooled for 15 subjects. The relation for the product of peak velocity and duration against amplitude, however, shows much less deviation with the correlation coefficient reaching a value as high as 0.96 .

\subsection{Main Sequence Relations and Asymmetry of the Velocity Profiles}

Exponential and linear regression functions were applied, respectively, for the fitting of the relationship between peak velocity and amplitude, and between duration and amplitude. In order to increase the correlation coefficients, mean values of the peak velocity and the duration were evaluated before regression analysis. With peak velocity saturated for amplitudes greater than $40^{\circ}$, the result is close to the previous experimental data [3]. Also, the duration is approximately proportional to the amplitude, which is coincident to the main sequence relations. Parameters evaluated after the fitting of regression functions are compared and shown in Table 3 for adductive and abductive saccades. The asymptote peak velocity is greater for the abductive saccades, indicating that the peak velocity is larger than the adductive under the same amplitude. The duration, however, shows no significant difference between the two. It was found that the asymptote peak velocity obtained in this study $\left(V_{a m}=632 \mathrm{deg} / \mathrm{sec}\right.$ for the abductive and 622 for the adductive) is larger than the values (520-578 deg/sec) obtained from previous investigations $[2-3,10]$, while

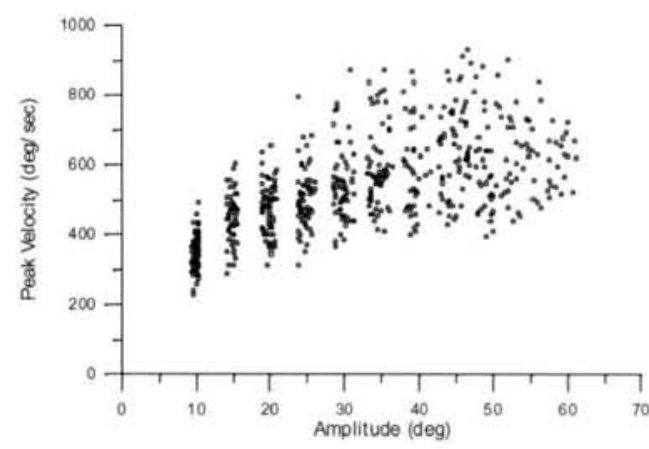

(a)

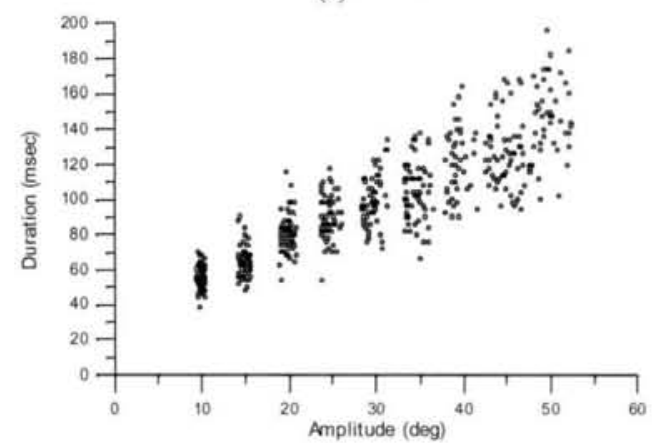

(b)

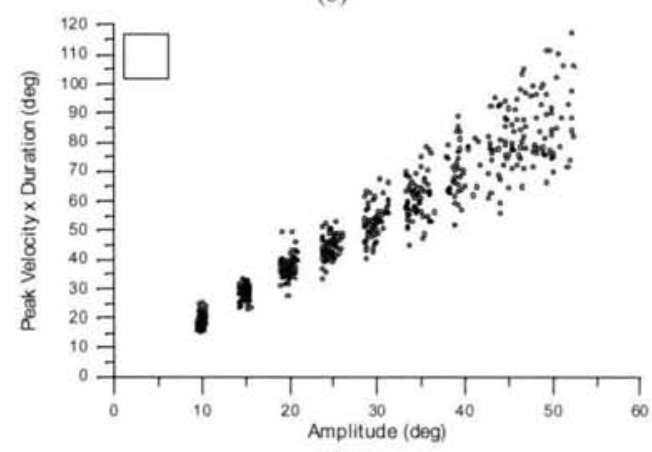

(c)

Fig 1. The relations for (a) peak velocity, (b) duration, and (c) the product of peak velocity and duration against amplitude for the abductive saccades. Although the former two show greater deviation, the later displays much less deviation. $\mathbf{N}=549$. 
the amplitudes for which the peak velocity reaches $63 \%$ of the asmptote values $\left(A_{0.63}=12.38 \mathrm{deg}\right.$ for the abductive and 12.98 for the adductive), which are larger than the result $\left(A_{0.63}=11.2\right)$ obtained by Collewijn et al. [3] and smaller than the values by Gangemi et al. $\left(A_{0.63}=23.4\right)$ [4] and Baloh et al. $\left(A_{0.63}=14\right)[2]$. For the duration and amplitude relationship, the slopes $(m=2.2 \mathrm{~ms} / \mathrm{deg}$ for both abductive and adductive) are within the range of typical value of $2-3 \mathrm{~ms} / \mathrm{deg}$ [11] while the intercepts $\left(y_{o}=30.1 \mathrm{~ms} / \mathrm{deg}\right.$ for the abductive and 32.6 for the adductive) lie between the value $\left(y_{0}=23\right)$ obtained by Collewijn et al. [3] and the result $\left(y_{o}=37\right)$ by Baloh et al. [2].

Acceleration fraction and skewness are also shown in Table 1 and 2. From the tables, we demonstrate that the asymmetry of the velocity profile increases with amplitude, which is agreed with the previous findings $[2-3,5,12]$. As shown in Figure 2, the relations for mean skewness and acceleration fraction of pooled abductive and adductive saccades against target amplitude are plotted.

\subsection{Acceleration and Deceleration Phases of the Velocity Profiles}

The exponential relations for acceleration time and acceleration amplitude against saccadic amplitude are shown in Figure 3(a) and 3(b), respectively, which are similar to the relationship between peak velocity and amplitude. Acceleration time is saturated for the amplitudes greater than $40^{\circ}$. The same results can be found in the previous experimental data [3] and the simulation result [13]. The relations for product of peak velocity and acceleration time $\left(V_{m} D_{a}\right)$ against acceleration amplitude $\left(A_{a}\right)$, and product of peak velocity and deceleration time $\left(V_{m} D_{a}\right)$ against deceleration amplitude $\left(A_{d}\right)$, are shown in Figure 4 for adductive and abductive saccades. Linear regression functions were applied to fit the data, which obtained very high correlation coefficients after the fitting. Adductive saccades show similar characteristics; only slopes obtained after regression fits are different for the acceleration phase. Estimated slopes $(m)$ indicated in Table 4 were further used for calculating the coefficients of Equations (3). Finally the saccadic amplitude was expressed as a function of acceleration time, deceleration time, and peak velocity, which contrasts with the previous work as a function of duration and peak velocity [4-5].

Table 1. The experimental results of adductive saccades.

\begin{tabular}{|c|c|c|c|c|c|c|c|c|c|c|c|}
\hline Amplitude (deg) & $10^{\prime \prime}$ & $15^{\circ}$ & $20^{\circ}$ & $25^{\circ}$ & $30^{\prime \prime}$ & $35^{\circ}$ & $40^{\prime \prime}$ & $45^{\circ}$ & $50^{\circ}$ & $55^{\prime \prime}$ & $60^{\circ}$ \\
\hline $\begin{array}{l}\text { Peak Velocity in } \\
\text { dcg/s }\left(\mathrm{SD}^{1}\right)\end{array}$ & $\begin{array}{l}350.7 \\
(47.3)\end{array}$ & $\begin{array}{l}446.4 \\
(71.2)\end{array}$ & $\begin{array}{l}472.9 \\
(73.4)\end{array}$ & $\begin{array}{l}503.1 \\
(85.7)\end{array}$ & $\begin{array}{c}543.3 \\
(102.3)\end{array}$ & $\begin{array}{c}591.5 \\
(112.8)\end{array}$ & $\begin{array}{c}594.4 \\
(124.1)\end{array}$ & $\begin{array}{c}618.2 \\
(126.9)\end{array}$ & $\begin{array}{c}601.2 \\
(126.0)\end{array}$ & $\begin{array}{c}623,6 \\
(118.2)\end{array}$ & $\begin{array}{l}615.3 \\
(69.1)\end{array}$ \\
\hline $\begin{array}{l}\text { Acceleration Time } \\
\text { in } \mathrm{ms}\left(\mathrm{SD}^{1}\right)\end{array}$ & $\begin{array}{l}24.2 \\
(5.2)\end{array}$ & $\begin{array}{l}27.6 \\
(6.9)\end{array}$ & $\begin{array}{l}32.7 \\
(7.8)\end{array}$ & $\begin{array}{l}33.0 \\
(7.9)\end{array}$ & $\begin{array}{l}34.2 \\
(8.4)\end{array}$ & $\begin{array}{l}36.4 \\
(9.5)\end{array}$ & $\begin{array}{c}38.9 \\
(15.5)\end{array}$ & $\begin{array}{c}38.5 \\
(14.4)\end{array}$ & $\begin{array}{c}40.8 \\
(16.7)\end{array}$ & $\begin{array}{c}42.7 \\
(16.2)\end{array}$ & $\begin{array}{c}34.8 \\
(11.6)\end{array}$ \\
\hline $\begin{array}{l}\text { Decelcration Time } \\
\text { in } \mathrm{ms}\left(\mathrm{SD}^{1}\right)\end{array}$ & $\begin{array}{l}29.9 \\
(4.8)\end{array}$ & $\begin{array}{l}36.7 \\
(9.4)\end{array}$ & $\begin{array}{l}47.3 \\
(8.3)\end{array}$ & $\begin{array}{c}56.5 \\
(10.9)\end{array}$ & $\begin{array}{c}65.4 \\
(13.8)\end{array}$ & $\begin{array}{c}69.1 \\
(13.4)\end{array}$ & $\begin{array}{c}82.1 \\
(18.1)\end{array}$ & $\begin{array}{c}87.5 \\
(18.9)\end{array}$ & $\begin{array}{l}104.8 \\
(23.4)\end{array}$ & $\begin{array}{l}111.8 \\
(23.3)\end{array}$ & $\begin{array}{l}136.3 \\
(16.1)\end{array}$ \\
\hline $\begin{array}{c}\text { Acceleration } \\
\text { Amplitude in deg } \\
\left(\mathrm{SD}^{1}\right)\end{array}$ & $\begin{array}{c}4.23 \\
(0.95)\end{array}$ & $\begin{array}{c}6.83 \\
(2.08)\end{array}$ & $\begin{array}{c}8.43 \\
(1.72)\end{array}$ & $\begin{array}{l}9.66 \\
(2.61)\end{array}$ & $\begin{array}{l}10.93 \\
(2.75)\end{array}$ & $\begin{array}{l}12.95 \\
(3.48)\end{array}$ & $\begin{array}{r}14.29 \\
(5.33)\end{array}$ & $\begin{array}{l}15.36 \\
5.57)\end{array}$ & $\begin{array}{l}15.58 \\
(6.22)\end{array}$ & $\begin{array}{l}16.25 \\
(6.65)\end{array}$ & $\begin{array}{l}14.19 \\
(5.87)\end{array}$ \\
\hline $\begin{array}{c}\text { Deceleration } \\
\text { Amplitude in deg } \\
\left(\mathrm{SD}^{1}\right)\end{array}$ & $\begin{array}{c}5.83 \\
(1.08)\end{array}$ & $\begin{array}{c}8.20 \\
(2.09)\end{array}$ & $\begin{array}{l}11.37 \\
(2.01)\end{array}$ & $\begin{array}{l}14.87 \\
(2.80)\end{array}$ & $\begin{array}{l}18.88 \\
(2.95)\end{array}$ & $\begin{array}{l}21.67 \\
(3.48)\end{array}$ & $\begin{array}{l}25.13 \\
(5.49)\end{array}$ & $\begin{array}{l}29.42 \\
(5.89)\end{array}$ & $\begin{array}{l}33.68 \\
(6.98)\end{array}$ & $\begin{array}{l}37.75 \\
(7.36)\end{array}$ & $\begin{array}{c}41.80 \\
(11.10)\end{array}$ \\
\hline $\begin{array}{l}\text { Duration in } \mathrm{ms} \\
\quad\left(\mathrm{SD}^{1}\right)\end{array}$ & $\begin{array}{l}54.1 \\
(5.9)\end{array}$ & $\begin{array}{l}64.3 \\
(8.8)\end{array}$ & $\begin{array}{c}79.9 \\
(10.8)\end{array}$ & $\begin{array}{l}89.5 \\
(11.9)\end{array}$ & $\begin{array}{c}99.6 \\
(14.1)\end{array}$ & $\begin{array}{l}105.4 \\
(16.4)\end{array}$ & $\begin{array}{r}121.0 \\
(19.2)\end{array}$ & $\begin{array}{l}126.0 \\
(19.5)\end{array}$ & $\begin{array}{l}145.7 \\
(21.5)\end{array}$ & $\begin{array}{r}154.6 \\
(14.9)\end{array}$ & $\begin{array}{l}171.1 \\
(13.9)\end{array}$ \\
\hline $\begin{array}{c}\text { Skewness }\left(\mathrm{SD}^{1}\right) \\
\mathbf{S}_{f}\end{array}$ & $\begin{array}{c}0.446 \\
(0.076)\end{array}$ & $\begin{array}{c}0.432 \\
(0.102)\end{array}$ & $\begin{array}{c}0.408 \\
(0.072)\end{array}$ & $\begin{array}{c}0.371 \\
(0.078)\end{array}$ & $\begin{array}{c}0.346 \\
(0.078)\end{array}$ & $\begin{array}{c}0.345 \\
(0.069)\end{array}$ & $\begin{array}{c}0.320 \\
(0.103)\end{array}$ & $\begin{array}{c}0.305 \\
(0.102)\end{array}$ & $\begin{array}{c}0.282 \\
(0.109)\end{array}$ & $\begin{array}{c}0.281 \\
(0.116)\end{array}$ & $\begin{array}{c}0.203 \\
(0.065)\end{array}$ \\
\hline $\mathrm{S}_{g}$ & $\begin{array}{c}0.783 \\
(0.089)\end{array}$ & $\begin{array}{c}0.831 \\
(0.101)\end{array}$ & $\begin{array}{c}0.849 \\
(0.092)\end{array}$ & $\begin{array}{c}0.927 \\
(0.097)\end{array}$ & $\begin{array}{c}0.976 \\
(0.111)\end{array}$ & $\begin{array}{c}0.999 \\
(0.105)\end{array}$ & $\begin{array}{c}1.080 \\
(0.112)\end{array}$ & $\begin{array}{c}1.095 \\
(0.102)\end{array}$ & $\begin{array}{c}1.167 \\
(0.123)\end{array}$ & $\begin{array}{c}1.190 \\
(0.094)\end{array}$ & $\begin{array}{c}1.263 \\
(0.110)\end{array}$ \\
\hline $\begin{array}{c}\text { Number of samples } \\
\text { for average }\end{array}$ & 93 & 55 & 64 & 62 & 59 & 63 & 43 & 61 & 45 & 33 & 17 \\
\hline
\end{tabular}

'SD- Standard deviation 
Table 2. The experimental results of abductive saccades.

\begin{tabular}{|c|c|c|c|c|c|c|c|c|c|c|c|}
\hline Amplitude (deg) & $10^{\circ}$ & $15^{\circ}$ & $20^{\circ}$ & $25^{\prime \prime}$ & $30^{\circ}$ & $35^{\circ}$ & $40^{\circ}$ & $45^{\circ}$ & $50^{\circ}$ & $55^{\circ}$ & $60^{\circ}$ \\
\hline $\begin{array}{l}\text { Pcak Velocity in } \\
\mathrm{dcg} / \mathrm{s}(\mathrm{SD})\end{array}$ & $\begin{array}{l}357.7 \\
(50.8)\end{array}$ & $\begin{array}{l}460.0 \\
(113.4)\end{array}$ & $\begin{array}{l}477.1 \\
(71.1)\end{array}$ & $\begin{array}{l}533.7 \\
(88.0)\end{array}$ & $\begin{array}{l}570.9 \\
(92.9)\end{array}$ & $\begin{array}{c}629.7 \\
(127.2)\end{array}$ & $\begin{array}{c}603.7 \\
(141.5)\end{array}$ & $\begin{array}{c}638.9 \\
(144.7)\end{array}$ & $\begin{array}{c}590.4 \\
(158.9)\end{array}$ & $\begin{array}{c}626.0 \\
(129.0)\end{array}$ & $\begin{array}{c}633.5 \\
(139.0)\end{array}$ \\
\hline $\begin{array}{l}\text { Accelcration time } \\
\text { in } \mathrm{ms}\left(\mathrm{SD}^{1}\right)\end{array}$ & $\begin{array}{l}23.8 \\
(4.8)\end{array}$ & $\begin{array}{l}28.5 \\
(5.6)\end{array}$ & $\begin{array}{l}30.8 \\
(6.6)\end{array}$ & $\begin{array}{l}31.3 \\
(8.5)\end{array}$ & $\begin{array}{l}32.0 \\
(5.7)\end{array}$ & $\begin{array}{l}32.3 \\
(6.9)\end{array}$ & $\begin{array}{c}34.3 \\
(10.4)\end{array}$ & $\begin{array}{l}34.0 \\
(7.9)\end{array}$ & $\begin{array}{l}35.3 \\
(7.8)\end{array}$ & $\begin{array}{c}36.7 \\
(11.2)\end{array}$ & $\begin{array}{r}35.6 \\
(8.8)\end{array}$ \\
\hline $\begin{array}{l}\text { Decelcration time } \\
\text { in } \mathrm{ms}\left(\mathrm{SD}^{1}\right)\end{array}$ & $\begin{array}{l}28.2 \\
(4.3)\end{array}$ & $\begin{array}{l}36.6 \\
(7.8)\end{array}$ & $\begin{array}{l}44.6 \\
(9.0)\end{array}$ & $\begin{array}{c}52.7 \\
(12.0)\end{array}$ & $\begin{array}{c}63.9 \\
(14.1)\end{array}$ & $\begin{array}{c}68.5 \\
(13.7)\end{array}$ & $\begin{array}{c}80.2 \\
(18.2)\end{array}$ & $\begin{array}{l}90.1 \\
(15.0)\end{array}$ & $\begin{array}{l}113.2 \\
(17.4)\end{array}$ & $\begin{array}{l}115.5 \\
(21.7)\end{array}$ & $\begin{array}{l}126.0 \\
(30.0)\end{array}$ \\
\hline $\begin{array}{l}\text { Acceleration } \\
\text { Amplitude in deg } \\
\left(\mathrm{SD}^{1}\right)\end{array}$ & $\begin{array}{c}4.33 \\
(0.87)\end{array}$ & $\begin{array}{c}7.17 \\
(1.43)\end{array}$ & $\begin{array}{c}8.61 \\
(1.78)\end{array}$ & $\begin{array}{l}10.04 \\
(2.75)\end{array}$ & $\begin{array}{l}11.40 \\
(2.82)\end{array}$ & $\begin{array}{l}12.68 \\
(3.17)\end{array}$ & $\begin{array}{r}13.29 \\
(4.41)\end{array}$ & $\begin{array}{l}13.82 \\
(3.39)\end{array}$ & $\begin{array}{l}13.59 \\
(3.76)\end{array}$ & $\begin{array}{l}15.16 \\
(5.08)\end{array}$ & $\begin{array}{l}16.03 \\
(6.87)\end{array}$ \\
\hline $\begin{array}{c}\text { Deceleration } \\
\text { Amplitude in deg } \\
\left(\mathrm{SD}^{1}\right)\end{array}$ & $\begin{array}{c}5.52 \\
(1.01)\end{array}$ & $\begin{array}{c}7.78 \\
(1.55)\end{array}$ & $\begin{array}{l}11.22 \\
(1.98)\end{array}$ & $\begin{array}{l}14.65 \\
(3.13)\end{array}$ & $\begin{array}{l}18.21 \\
(3.13)\end{array}$ & $\begin{array}{l}21.74 \\
(3.69)\end{array}$ & $\begin{array}{l}26.02 \\
(4.27)\end{array}$ & $\begin{array}{l}30.51 \\
(3.94)\end{array}$ & $\begin{array}{l}35.08 \\
(5.36)\end{array}$ & $\begin{array}{l}39.48 \\
(5.35)\end{array}$ & $\begin{array}{l}41.89 \\
(8.00)\end{array}$ \\
\hline $\begin{array}{l}\text { Duration in ms } \\
\quad\left(\mathrm{SD}^{1}\right)\end{array}$ & $\begin{array}{r}52.0 \\
(5.4)\end{array}$ & $\begin{array}{l}65.1 \\
(9.6)\end{array}$ & $\begin{array}{c}75.5 \\
(10.0)\end{array}$ & $\begin{array}{c}83.9 \\
(12.3)\end{array}$ & $\begin{array}{c}95.8 \\
(13.1)\end{array}$ & $\begin{array}{l}100.8 \\
(14.0)\end{array}$ & $\begin{array}{r}114.5 \\
(18.2)\end{array}$ & $\begin{array}{l}124.1 \\
(16.6)\end{array}$ & $\begin{array}{r}148.5 \\
(17.7)\end{array}$ & $\begin{array}{l}152.2 \\
(20.0)\end{array}$ & $\begin{array}{l}161.6 \\
(24.4)\end{array}$ \\
\hline $\begin{array}{c}\text { Skewness }\left(\mathrm{SD}^{1}\right) \\
\mathrm{S}_{f}\end{array}$ & $\begin{array}{c}0.457 \\
(0.072)\end{array}$ & $\begin{array}{c}0.438 \\
(0.075)\end{array}$ & $\begin{array}{c}0.410 \\
(0.078)\end{array}$ & $\begin{array}{c}0.375 \\
(0.095)\end{array}$ & $\begin{array}{c}0.339 \\
(0.071)\end{array}$ & $\begin{array}{c}0.324 \\
(0.069)\end{array}$ & $\begin{array}{c}0.303 \\
(0.082)\end{array}$ & $\begin{array}{c}0.275 \\
(0.057)\end{array}$ & $\begin{array}{c}0.239 \\
(0.053)\end{array}$ & $\begin{array}{c}0.244 \\
(0.075)\end{array}$ & $\begin{array}{c}0.231 \\
(0.093)\end{array}$ \\
\hline $\mathrm{S}_{g}$ & $\begin{array}{c}0.781 \\
(0.087)\end{array}$ & $\begin{array}{c}0.782 \\
(0.108)\end{array}$ & $\begin{array}{c}0.863 \\
(0.109)\end{array}$ & $\begin{array}{c}0.908 \\
(0.102)\end{array}$ & $\begin{array}{c}0.946 \\
(0.121)\end{array}$ & $\begin{array}{c}0.981 \\
(0.132)\end{array}$ & $\begin{array}{c}1.050 \\
(0.137)\end{array}$ & $\begin{array}{c}1.074 \\
(0.112)\end{array}$ & $\begin{array}{c}1.157 \\
(0.131)\end{array}$ & $\begin{array}{c}1.165 \\
(0.151)\end{array}$ & $\begin{array}{c}1.161 \\
(0.166)\end{array}$ \\
\hline $\begin{array}{c}\text { Number of samples } \\
\text { for average }\end{array}$ & 116 & 62 & 51 & 65 & 59 & 57 & 50 & 66 & 46 & 49 & 28 \\
\hline
\end{tabular}

'SD- Standard deviation

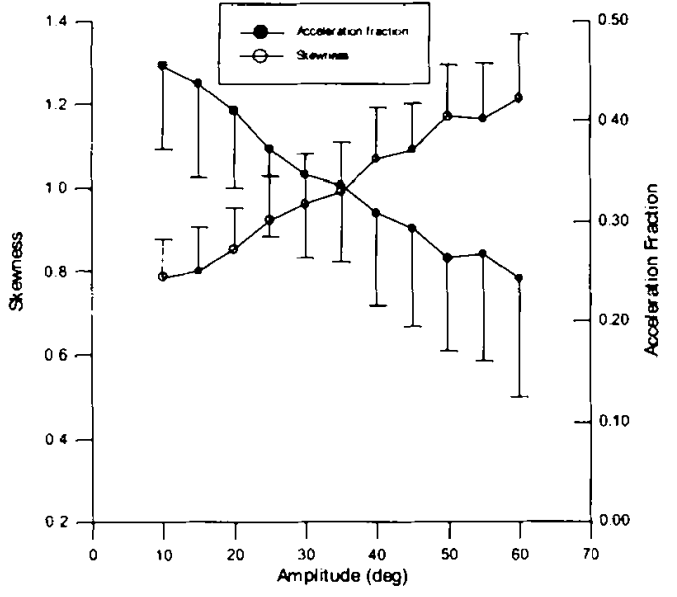

Fig 2. The relations for skewness and acceleration fraction against saccadic amplitude.

\section{DISCUSSION AND CONCLUSION}

In this study, we pooled together the data of 15 young subjects for investigating saccade charateristics. As shown in Figure 1, peak velocity displays great scattering ( $R=0.72)$, while duration $(\mathrm{R}=0.89)$ and the product of peak velocity and duration $(\mathrm{R}=0.96)$ against amplitude for the pooled data demonstrate less deviation. As indicateted in Figure 4, the relations for $V_{m} D_{a}$ against acceleration amplitude and $V_{m} D_{d}$ against deceleration amplitude were also fitted with very high correlation coefficients $(R=0.93-0.96)$. This demonstrates that the intra- and inter-subject variance is small for the relationship between $V_{m} D$ and saccadic amplitude, which makes it reasonable to study the acceleration and deceleration phases by pooling the data together.

The saturation of peak velocity marks the frequency limitation of burst neurons in generating bursts. It was found that the acceleration time was also saturated with $\mathrm{A}_{0.63}$ close to the value obtained from the peak velocity. Figure 3(a) shows that the acceleration time is increased with amplitude for amplitudes below $40^{\circ}$ and saturates at $40^{\circ}-50^{\circ}$. The acceleration amplitude, as shown in Figure 3(b), in comparison, saturates at a higher saccadic amplitude for both abductive and adductive saccades. By comparing our data with the simulation results, it can be observedthta the duration of both acceleration and deceleration phases increase with amplitude for small amplitudes, while the acceleration phase is saturated for large saccades and only the deceleration phase increases with amplitude. 


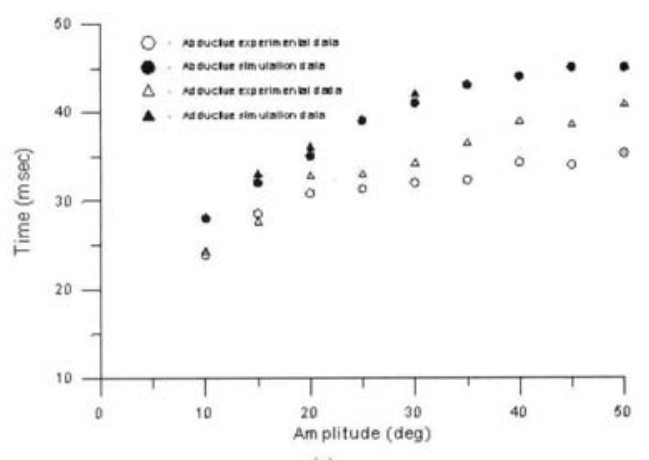

(a)

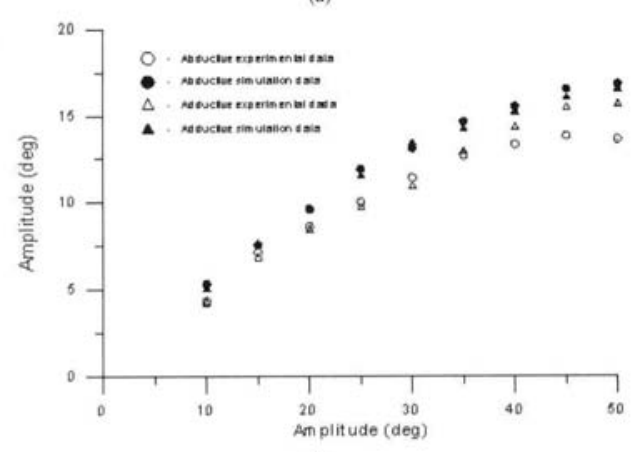

(b)

Fig 3. Comparison of simulation results and experimental data for (a) acceleration time and (b) acceleration amplitude against saccadic amplitude.

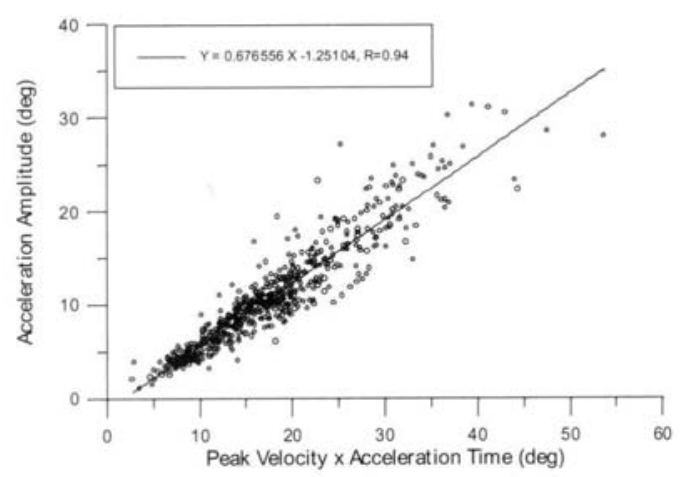

(a)

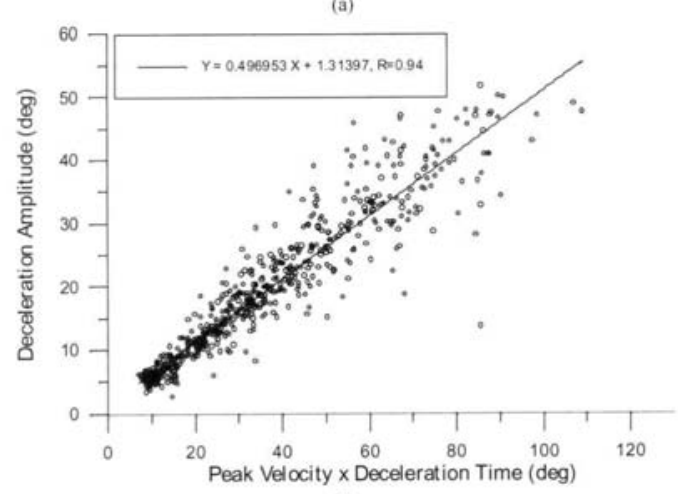

(b)
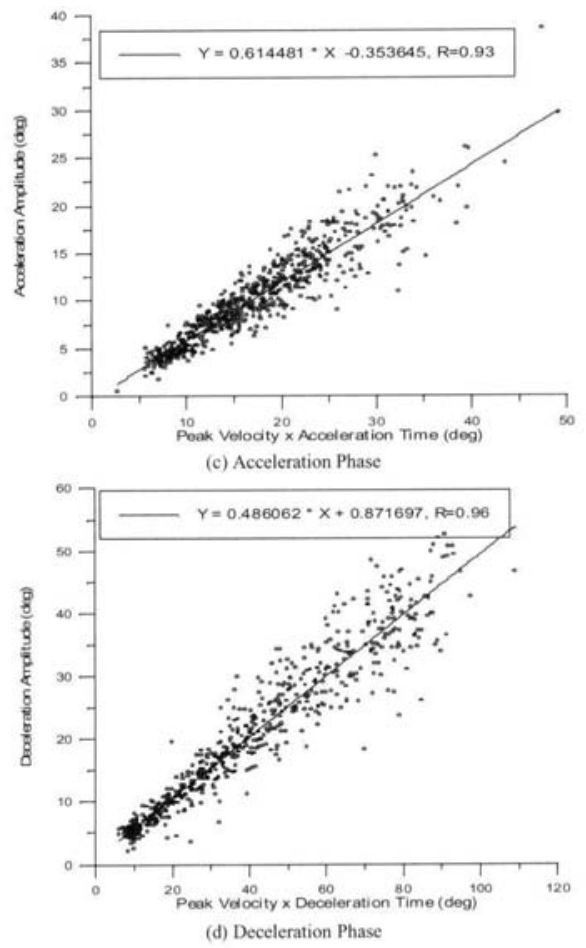

Fig 4. The relations for (a) the product of peak velocity and acceleration time against acceleration amplitude and (b) the product of peak velocity and deceleration time against deceleration amplitude for the adductive saccades (c) the product of peak velocity and acceleration time against acceleration amplitude and (d) the product of peak velocity and deceleration time against deceleration amplitude for the abductive saccades. $N=651$.

Although the main sequence relations are very stereotyped, they, however, cannot depict the saccadic trajectories efficiently. As pointed out by Baloh et al. [2], the velocity profiles for various saccadic amplitudes were significantly skewed as the amplitude increased. Table 4 shows the parameters obtained in this study and demonstrates that the shape of the acceleration phase $\left(n_{l}=2.09\right.$ for the adductive and 1.59 for the abductive) approximates a parabola for the velocity profile, and to a line for the deceleration phase ( $n_{2}=0.99$ for the adductive and 0.95 for the abductive). This finding can be explained by the results obtained in the previous works [3,5]. In the study of Van Opstal and Van Gisbergen [5], the velocity profiles were normalized with peak velocity and duration for various amplitudes. Where the acceleration phase of individual amplitude was similar to the curve shown in Equation (3), the deceleration phase changed into a line as amplitude increased. The profiles obtained by Collewijn et al. [3], in contrast, showed outward 
Table 3. Main sequence relations and exponential regression fit for the acceleration time as a function of amplitude.

\begin{tabular}{c|ccc|ccc|ccc}
\hline & \multicolumn{3}{|c|}{ Peak velocity } & \multicolumn{3}{c|}{ Duration } & \multicolumn{3}{c}{ Acceleration time } \\
\cline { 2 - 10 } & $V_{a m}$ & $A_{0.63}$ & $R$ & $y_{0}$ & $m$ & $R$ & $D_{a a}$ & $A_{0.63}$ & $R$ \\
\hline Adductive & 622.0 & 12.98 & 0.983 & 32.621 & 2.203 & 0.996 & 40.6 & 13.04 & 0.960 \\
Abductive & 631.9 & 12.38 & 0.972 & 30.103 & 2.202 & 0.993 & 34.6 & 9.06 & 0.952 \\
\hline
\end{tabular}

Table 4. Linear regression fits for the acceleration and the deceleration phases of the abductive and the adductive saccades.

\begin{tabular}{c|cccc|cccc}
\hline & \multicolumn{4}{|c|}{ Acceleration Phase } & \multicolumn{4}{c}{ Deceleration Phase } \\
\cline { 2 - 8 } & $y_{0}$ & $m$ & $n_{1}$ & $R$ & $y_{0}$ & $m$ & $n_{2}$ & $R$ \\
\hline Adductive & 1.251 & 0.677 & 2.09 & 0.94 & 1.314 & 0.497 & 0.99 & 0.94 \\
Abductive & -0.354 & 0.614 & 1.59 & 0.93 & 0.872 & 0.486 & 0.95 & 0.96 \\
\hline
\end{tabular}

bending at the initial stage of the deceleration phase and inward bending at the following stage. As shown in Figure 5 of the simulation profiles, the area under the curve (amplitude) increased by the outward effect was compensated by the inward profile, which made the deceleration profile equal to a line. In conclusion, our method in finding the shape parameters of the velocity profile proposes an alternative in the quantitative analysis of saccadic dynamics.

\section{ACKNOWLEDGEMENT}

This work was supported by National Science Council of Taiwan, Grant No. NSC91-2213-E-166001 .

\section{REFERENCES}

1. Bahill AT, Clark MR, Stark L. The main sequence, a tool for studying human eye movements. Math Biosci, 24:191-204, 1975.

2. Baloh RW, Konrad HR, Sills AW, Honrubia WE. The saccade velocity test. Neurology, 25:1071-1076, 1975.

3. Collewijn H, Erkelens CJ, Steinman RM. Binocular co-ordination of human horizontal saccadic eye movements. J Physiology, 404:157-182, 1988.

4. Evinger C, Kaneko CRS, Fuchs AF. Oblique saccadic eye movements of the cat. Exp Brain Res, 41:370-379, 1981.

5. Van Opstal AJ, Van Gisbergen JAM. Skewness of

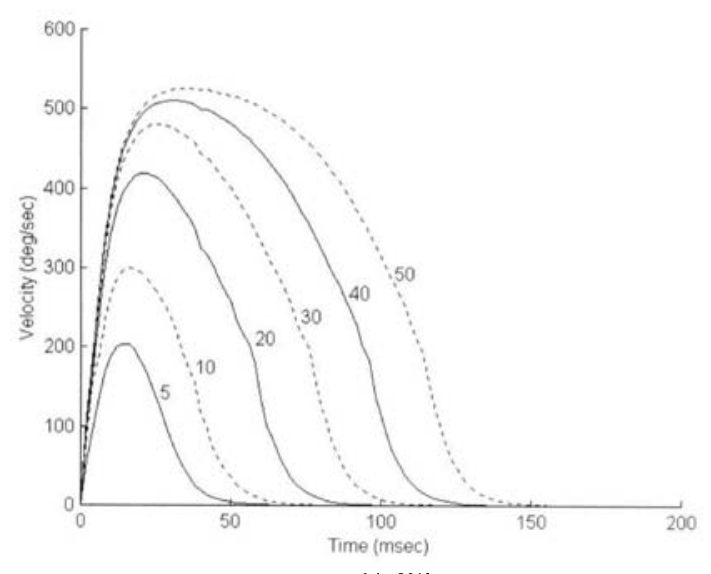

Fig 5. Velocity profiles generated by the models proposed by Van Gisbergen et al. (1981).

saccadic velocity profiles: a unifying parameter for normal and slow saccades. Vision Res, 27:731-745, 1987.

6. Smit AC, Van Gisbergen JAM, Cools AR. A parametric analysis of human saccades in different experimental paradigms. Vision Res, 27:1745-1762, 1987.

7. Chen Y-F, Chen T, Lin H-H, Tsai T-T. Quantitative Description of Saccadic Dynamics: Application of a Rational Power Function. Submitted.

8. Pelisson D, Prablanc C. Kinematics of centrifugal and centripetal saccadic eye movements in man. Vision Res, 28:87-94, 1988. 
9. Chen Y-F, Lin H-H, Chen T, Tsai T-T, Shee I-F. The peak velocity and skewness relationship for the reflexive saccades. Biomed Eng Appl Basis Comm, 14:71-80, 2002.

10. Gangemi PF, Messori A, Baldini S, Parigi A, Massi S, Zaccara G. Comparison of two nonlinear models for fitting saccadic eye movement data. Comput Methods Programs Biomed ;34:291-297, 1991 .

11. Becker W. Saccades, In: Eye movements, Edited by Carpenter RHS. MacMillan, 1991.

12. Takagi M, Abe H, Hasegawa S, Yoshizawa T, Usui T. Velocity profile of human horizontal saccades. Ophthalmologica, 206:169-176,1993.

13. Harris CM, Wolpert DM. Signal-dependent noise determines motor planning. Nature, 394:780-784, 1998.
14. Leigh RJ, Zee DS. The neurology of eye movements, 3rd Ed. New York: Oxford Univ Press, 1999.

15. Chen T, Chen Y-F, Lin C-H, Tsai T-T. Quantification analysis for saccadic eye movements. Ann Biom Eng, 26:1065-1071, 1998.

16. Chen Y-F, Chen T, Tsai T-T. Analysis of volition latency on antisaccadic eye movements. Med Eng Phy, 21:555-562, 1999.

17. Chen Y-F, Lin H-H, Huang K-H, Chen T, Tsai T-T. Study of velocity profiles for saccadic eye movements. Proc METMBS, 293-296, 2001. 